\title{
3D PRINTERS - NEW POSSIBILITIES IN EDUCATION
}

\author{
Joanna Szulżyk-Cieplak', Aneta Duda', Bartłomiej Sidor \\ 1 Faculty of Fundamentals of Technology, Lublin University of Technology, Nadbystrzycka 38, 20-618 Lublin, \\ Poland, e-mail: j.szulzyk-cieplak@pollub.pl
}

Received: 2014.09 .25

Accepted: 2014.10.25

Published: 2014.12.01

\begin{abstract}
In the last few years a significant growth of three-dimensional printing has been noticed. Although 3D printers have been around for about 30 years, they were very expensive, that is why they were available in the industry only in the majority. In recent years, prices of 3D printers have fallen more than tenfold, owing to the fact they are used not only in large enterprises but also in all kinds of educational institutions, small businesses or in do-it-yourself men's houses. They are, inter alia, used to construct physical models, so much needed in education. Nowadays, one of the most popular 3D printing technologies is FDM (Fused Deposition Modeling). Relatively low prices of printers in this technology make them available for almost everyone. The paper discusses the technology of rapid prototyping, with particular emphasis on the use of $3 \mathrm{D}$ printing and appropriately matched printer to designed laboratory stand.
\end{abstract}

Keywords: 3D printer, 3D scanner, 3D print.

\section{INTRODUCTION}

In recent years, there are many discussions about the problems of higher education, unemployment among graduates, fields of study mismatch to the market, etc. Wondering how to overcome these weaknesses, it is necessary to look for new forms of engineering education, because there is an impression that traditional education, in the changing world, "does not keep up" with fast development. One of the tasks educational system is facing is developing engineering characteristics favoring innovation [1].

Education in the field of rapid prototyping technology perfectly fits this trend. In the United Kingdom, educational programs using 3D printers began to show up [16]. Classes are also more interesting for students, allowing them to broaden their knowledge not only in theory but also in practice. They have a remarkable effect on imagination, so owing to them, children's ideas can be converted into real projects. Three-dimensional printing technology is also becoming more widely used in higher education. Printers are used there not only for research but also for educational pur- poses. They are not only a curiosity but diversify classes by using 3D technology, which become more attractive and expand the scope of thematic application of the classes [3].

\section{TECHNOLOGIES OF RAPID PROTO- TYPING IN THE PROCESS OF DESIGN AND PREPARATION OF PRODUCTION}

Rapid prototyping is a term used to describe a set of methods for rapid, precise and repetitive production of elements in incremental technology, usually with the use of a computer. Introduction of rapid prototyping has revolutionized prototyping. Instead of a long, laborious process of creation of models and prototypes it has become much faster. In prototyping, the model is created in layers, which distinguishes it from traditional processing methods, in which elements are created by removing material from a prefabricated product. An important characteristic distinguishing prototyping from traditional methods of processing planning is a changed designing system. Another element which affects the advantage of 
prototyping over decrement method is the possibility to create complex structures, such as a hollow sphere [3, 8]. Models created by rapid prototyping are made and designed faster than elements in traditional methods. A comparison of these two methods is shown in Figure 1.

a)

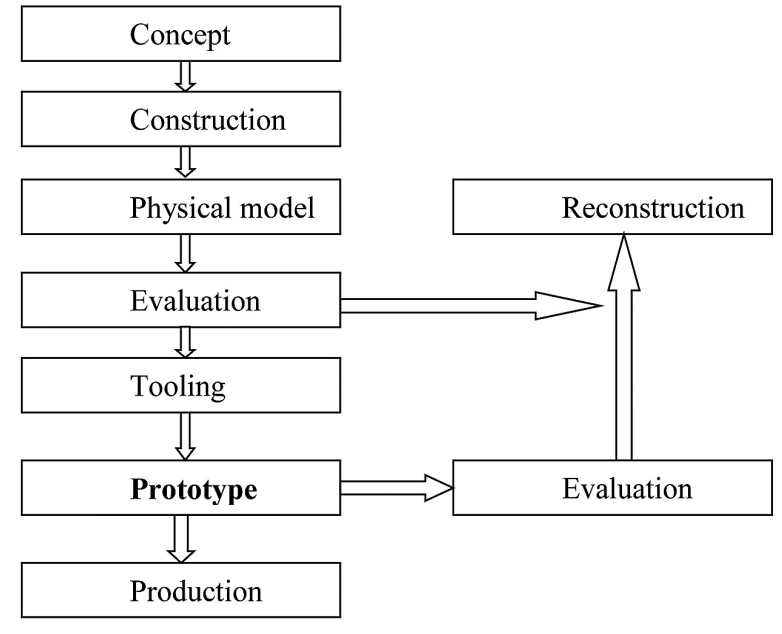

b)

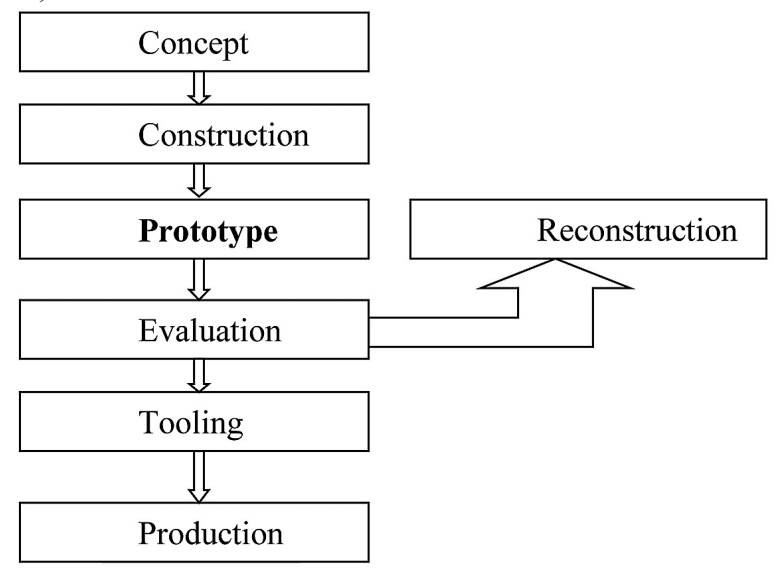

Fig. 1. Scheme of the process of introducing new product to the market: a - traditional approach, $\mathrm{b}$ - using rapid prototyping

\section{D SCANNING}

In order to obtain a three-dimensional model of a given object, it does need to be modelled or searched on the Internet. 3D scans allow for obtaining the model. It is a device that carries actual shape, three-dimensional geometry to digital form. This process in some cases accelerates designing and work in some occupations [2, 4].

$3 \mathrm{D}$ scanning is used in reverse engineering, that is in the process of obtaining informa- tion of a given object, necessary to construct its equivalent. There are also other applications of this technology. It is often necessary in medicine - for instance in selecting an ideal prosthesis for an individual patient. It is also used in museums (Figure 2) to create digital models of buildings or small exhibits. Three-dimensional scanning technology is also used computer graphics to create, inter alia, games.

Autodesk 123D Catch gives a very interesting option of three-dimensional scanning. This program allows for scanning on the basis of photos. It is enough to make several or a dozen pictures of selected object. The photos have to be taken all around at different angles. Then, the pictures are sent and analyzed in the cloud, which is an additional advantage because it does not burden our computer. All the process takes a few minutes and eventually we receive the model that latter can be worked on in other CAD software. 123 CAD except the version for Windows is also available for iOS [9].

In the future, having enough amount of money, 3D scanner can be placed on our desk next to the 3D printer - such a set is ra eal three-dimensional copy machine. This refers to the Digitizer scanned made by MarkerBot. This 3D scanner will be intended for home users. Owing to it and 3D printer, everyone, even without designing skills, will be able to duplicate some items quite as easily as photo copier. It is interesting that having digital model, it will be possible to send it to someone who will print it on $3 \mathrm{D}$ printer. Unfortunately, this scanner is currently not available for sale [5].

\section{EQUIPMENT AND MATERIALS USED IN RAPID PROTOTYPING TECHNOLOGY}

Number of 3D printer applications is still increasing They can print with various materials, for instance: plastic, metal, imitation of glass, titanium, silver or gold, and even chocolate. Scientists are moving much further and are still looking for new applications for threedimensional printers. The team from University of Southern California developed a method of houses creation in 3D printing technology [12]. In contrast, NASA is working on developing a prototype of 3D printer that will print food. It is one of the stages of preparation for manned mission to Mars. Figure 3 presents the visualization of houses printing $[10,13]$. 


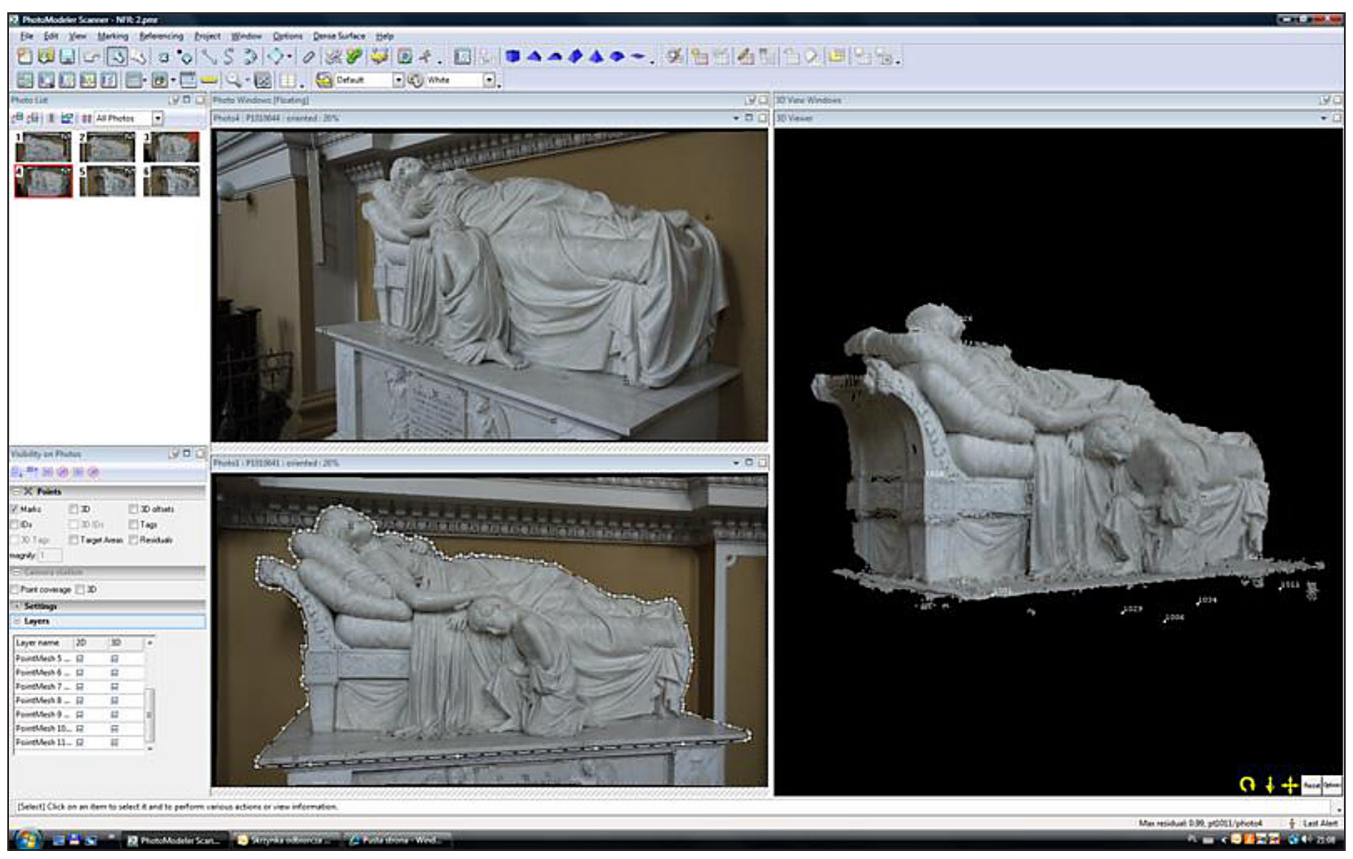

Fig. 2. 3D scanning of the Tomb of Mary Krasinska in Opinogora [15]

Producers of 3D printers are trying to find clients not only in large companies, research or educational institutions, but also in households. An interesting alternative to currently expensive printers is Rep-Rap project [14]. It was developed by Adrian Bowyer at the University of Bath in the United Kingdom. Its main concept is to create a self-replicating machine, in the form of 3D printer. This machine works in FDM technology.

Currently, the produced machines are able to print $70-80 \%$ of the parts required to make the next printer. It is necessary to remember that this is the printer to be independently assembled. Unexperienced user will do it in 2-3 days. All schemes, instructions are published under GNU license, that is, they are available on the Internet, for free, and anyone can modify them in any way. Figure 4 shows the "mother" printer and its two "children" $[6,14]$.

$3 \mathrm{D}$ printer is needed not only for do-ityourself enthusiasts. We will find many uses in house:. phone case, and cover for damaged electric kettle, as well as glasses frame, a fragment of broken toy or Lego. Plastic car elements can also be printed - for instance, switch to windows for rare or historic car with parts hard to buy. Only three-dimensional model of the part you want to print is needed. It can be designed by ourselves or downloaded complete model from the Internet. Within 5-10 years, this branch of industry is predicted to significantly develop that $3 \mathrm{D}$ printer will be available in a computer store in the same way as an ordinary $2 \mathrm{D}$ printer [5].

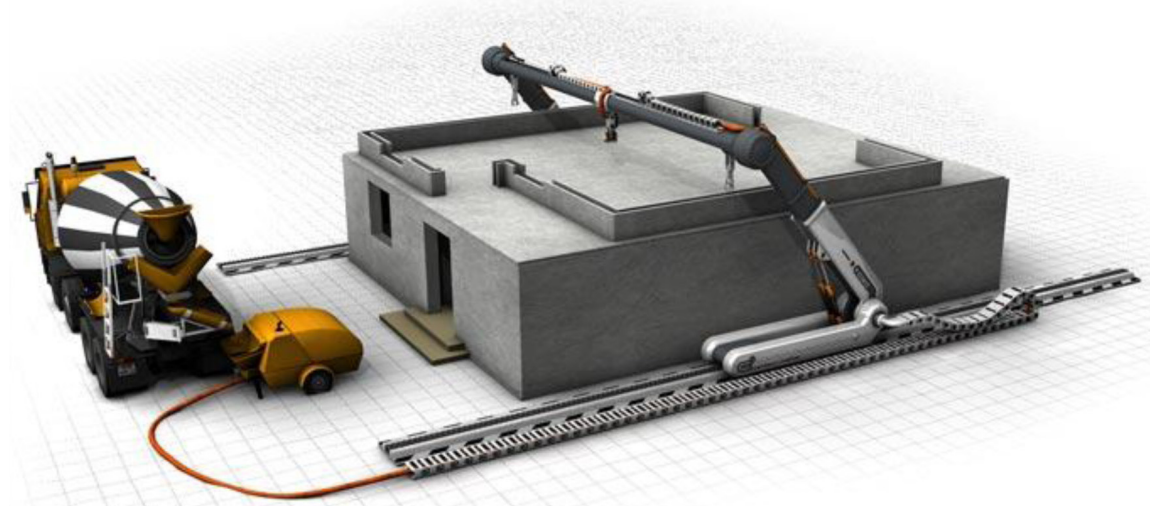

Fig. 3. Visualization of houses' printing [13] 


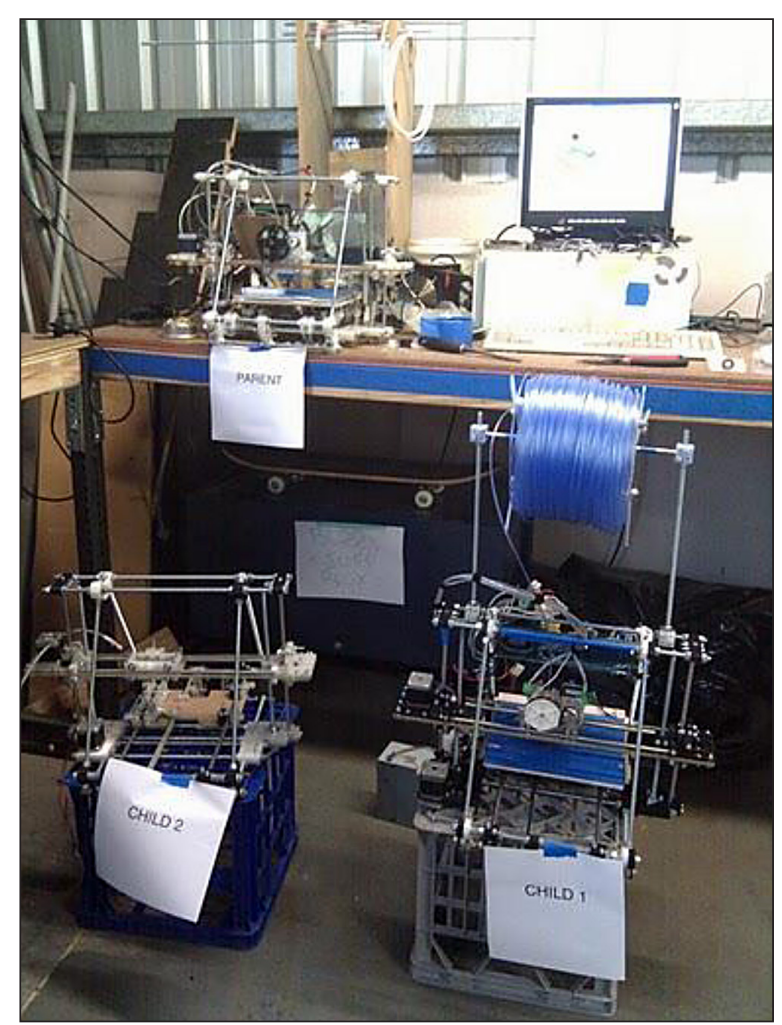

Fig. 4. Rep-Rap printers [14]

\section{LABORATORY STAND FOR RAPID PROTOTYPING}

On the basis of the review of 3D printers available on the Polish market, laboratory stand equipped with $3 \mathrm{D}$ printer, designed for didactic purposes, e.g. simulation and visualization of technological processes, has been developed. When designing the stand, the following criteria were taken into account: printer cost, printer parameters, printer usage environment and didactic application.

Theoretically, the stand should be a group of devices enabling construction and analysis of complex CAD models. The set matched to the needs of laboratory stand should be so efficient to allow free use of the program for three-dimensional modelling without a problem. This stand should be equipped with CAD software which is easy to use and has transparent interface. The main element of the stand will be a 3D printer working in FDM technology, which is able to print from the following materials: ABS, PLA, PVA, Nylon. Work area of 3D printer should not be smaller than $200 \times 200 \times 200 \mathrm{~mm}$, and minimum thickness of the layer should not be equal more than $0,2 \mathrm{~mm}$.

\section{D PRINTER PARAMETERS}

When reviewing popular models of 3D printers, the model that meets all design assumptions has been selected. Taking into account work area, which is included in design requirements and a number of other factors, Leapfrog Creatr has been selected (Figure 5). This device uses an incremental technology of model building consisting in layered applying of thermoplastic material through a hot nozzle (FDM technology). The printer can print models not only from the materials listed in the design assumptions, but also from other materials. Minimum layer thickness (Table 1) is much smaller than the assumptive, which is another advantage of selected printer. The selected printer has two print nozzles, which allows for printing of two different materials simultaneously, for instance: from the model material and supporting one. An additional advantage is built-up work area. Owing to this solution, the printed object is protected against external factors such as: wind gusts that affect print quality very adversely. The printer software is free, which eliminates additional costs. Selected printers can work on Windows and Mac. Faculty of Fundamentals of Technology has license it for Windows 7, which is fully supported by selected printer. Among printers in a similar price range, choice of Leapfrog Creatr printer is the best option.

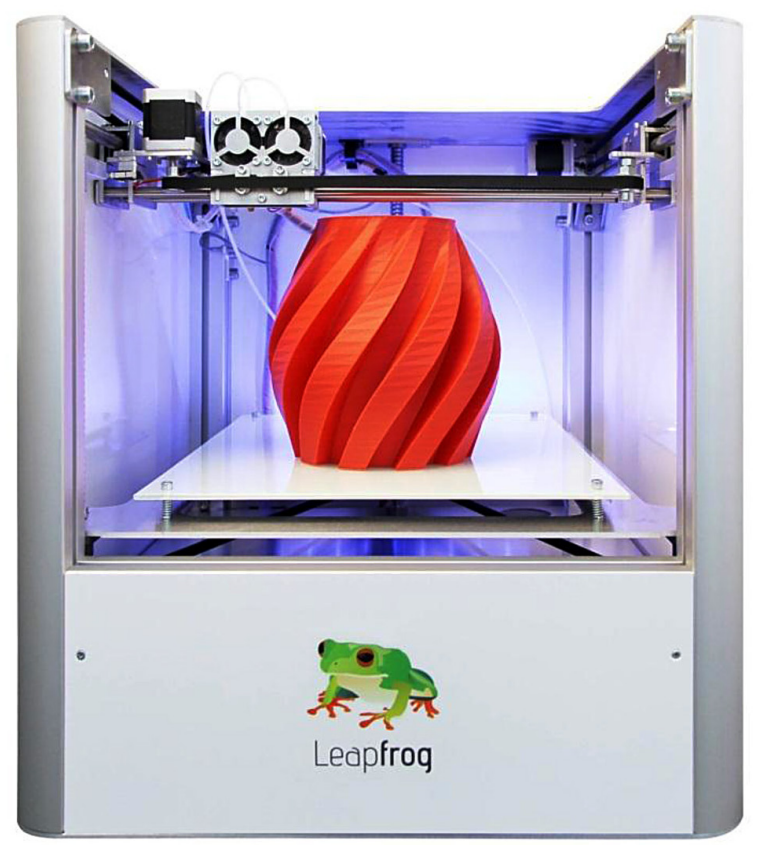

Fig. 5. Leapfrog Creatr printer [17] 
Table 1. Specifications of Leapfrog Creatr printer

\begin{tabular}{|l|c|}
\hline Outer dimensions $(\mathrm{L} \times \mathrm{W} \times \mathrm{H})$ & $500 \times 600 \times 500 \mathrm{~mm}$ \\
\hline Build size $(\mathrm{L} \times \mathrm{W} \times \mathrm{H})$ & $230 \times 270 \times 210 \mathrm{~mm}$ \\
\hline Max. print volume & $13,7 \mathrm{I}$ \\
\hline Positioning accuracy & $0,05 \mathrm{~mm}$ \\
\hline Layer thickness & $0,05 \mathrm{~mm}$ \\
\hline Electrical connection & \begin{tabular}{c}
$100-240 \mathrm{~V}$ \\
\hline Material types
\end{tabular} \\
\hline Extruder size & $\begin{array}{c}\text { Nylon, LayBrick } \\
0,35 \mathrm{~mm}\end{array}$ \\
\hline Speed $\mathrm{X}$ and $\mathrm{Y}$ axis & do $0,35 \mathrm{~m} / \mathrm{s}$ \\
\hline Production speed & ok. $2 \mathrm{~cm} / \mathrm{min}$ \\
\hline Power consumption & $400 \mathrm{~W}$ \\
\hline Price & $7500 \mathrm{PLN}$ \\
\hline
\end{tabular}

\section{SELECTION OF STAND ELEMENTS}

Efficient CPU with a large monitor is required for comfortable work with CAD software. Therefore, Asus M51AC-PL005S has been selected. It is equipped with quad-core Intel Core i7-4770, powerful graphic card nVidia Ge Force GTX 760. It also has 8GB RAM and 1 TB hard drive. LED Full HD (1920 x 1080 px) Monitor IIYAMAProLiteB2780HSU 27" with time reaction equal $2 \mathrm{~ms}$ has been selected. The set was also equipped with professional mouse and keyboard Logitech mk710 (Table 2).

Taking into account the fact that Faculty of Fundamentals of Technology has licenses for Windows 7, there is no need to buy it for selected CPU. Since the Faculty has also package AutoCAD Design Suite Ultimate 2013, Autodesk Inventor Professional included in the abovementioned package has been selected as CAD software. It is easy to use, has transparent interface that simplifies the user work, so fully meets designing assumptions. This choice allows for elimination of additional costs of purchasing expensive CAD software license.

Table 2. Preliminary estimate of designed stand

\begin{tabular}{|c|l|c|}
\hline No. & \multicolumn{1}{|c|}{ Description } & Price \\
\hline 1 & 3D LeapfrogCreatr printer & 7500 PLN \\
\hline 2 & CPU Asus M51AC-PL005S & 4000 PLN \\
\hline 3 & Monitor IIYAMAProLiteB2780HSU & 1200 PLN \\
\hline 4 & Keyboard and mouse Logitech mk710 & 350 PLN \\
\hline \multicolumn{2}{|c|}{ Total } & 13050 PLN \\
\hline
\end{tabular}

\section{CONCLUSION}

3D printing technology is undoubtedly new chapter in teaching. 3D printers directly support teaching process. Printed models facilitate better understanding of the creation process. They also enhance students' involvement in the classes. 3D printing allows the students to transfer their ideas into reality. The students who can physically examine their projects, more enthusiastically participate in the classes, and their abilities of spatial imagination are effectively stimulated. Printed models allow the students to learn about the strengths and weaknesses of their projects.

In the study, there was designed laboratory stand for rapid prototyping using Leapfrog Creatr 3D printer. This stand will be used for teaching purposes, such as simulation and visualization of technological processes. During the analysis of popular 3D printers available on the market, one which meets all design assumptions has been selected. Decision was made on the basis of printing precision, built size, quantity and diversity of materials used for printing, minimum layer thickness, as well as additional factors that affect printer selection. Moreover, designed stand has been equipped with efficient computer set including CPU with professional graphic card and high-end processor, large LED Full HD monitor, as well as professional keyboard and mouse.

\section{REFERENCES}

1. Bergmann C., Linder M.: 3D printing of bone substitute implants using calcium phosphate and bioactive glasses. Journal of the European Ceramic Society 30, 2010, 2563-2567.

2. Bubicz M.: Raport: szybkie prototypowanie cz. I. Projektowanie i Konstrukcje Inżynierskie 07, 2008, Wydawnistwo Iter, Gdańsk 2008, 14-26.

3. Chlebus E.: Innowacyjne technologie RapidPrototyping - RapidTooling w rozwoju produktu. Oficyna Wydawnicza Politechniki Wrocławskiej, 2003.

4. Chuchro M., Czekaj J., Ruszaj A.: Seminarium: Techniki szybkiego prototypowania w cyklu życia produktu. Mechanik nr 12, 2008, 1063-1070.

5. Czerwiński M., Czerwiński K.: Drukowanie w 3D. Wydawnictwo Infoaudit, Warszawa 2013.

6. Griffin M.: Ultimate 3D Printer Buyer's Guide Make. Wydawnictwo O'Reilly Media, Inc., USA 2012, 38-78. 
7. Hopkinson N., Hague R., Dickens P.: Rapid manufacturing: An industrial revolution for the digital age. Wydawnictwo Wiley, 2006, p. 56.

8. Miecielica M.: Techniki szybkiego prototypowania - RapidPrototyping. Przegląd Mechaniczny 02, 2010, 39-45.

9. Wajand J.A, Wajand J.T,: Tłokowe silniki spalinowe średnio- i szybkoobrotowe. Wydanie czwarte. WNT, Warszawa 2005.

10. Wittbrodt B.T., Glover A.G.: Life-cycle economic analysis of distributed manufacturing with opensource 3-D printers. Mechatronics 23, 2013, 713-726.
11. http://www.popsci.com/technology/article/201208/researcher-aims-print-3-d-print-entire-housesout-concrete-20-hours

12. http://domowe2013.pl/ocieplanie-rozwiazanieekonomiczne/

13. http://reprap.org/wiki/RepRap/pl

14. http://www.fotoskaner.pl/digitalizacja/category/ pracujemy

15. http://www.przyrostowo.pl/artykuly/drukarki-3dw-edukacji-szkolnej-w-wielkiej-brytanii

16. www.lpfrg.com 